\title{
ОСОБЕННОСТИ ТЕЧЕНИЙ В ВЕРХНИХ БЬЕФАХ КРУПНЫХ ГЭС, СВЯЗАННЫХ С НЕРАВНОМЕРНОСТЬЮ ПРОПУСКА ЧЕРЕЗ НИХ ВОДЫ
}

\author{
А.П. Лепихин, А.В. Богомолов, А.А. Тиунов \\ Горный институт УрО РАН, г. Пермь
}

Аннотация: На примере Камской ГЭС рассматриваются особенности формирования инерционных течений в верхних бьефах крупных гидроузлов при резких изменениях расходов сброса воды. Проведено сопоставление изменений расходов сбросов с измеряемыми в течение суток скоростями и направлениями течений на Чусовском плесе Камского водохранилища, а также с результатами гидродинамического моделирования в приближении «мелкой» воды. Показано, что при резком уменьшении расходов сбросов наблюдается формирование обратных течений.

Ключевые слова: Водохранилища, верхний бьеф, обратные течения, моделирование.

Характерной особенностью ГЭС является технологическая возможность оперативного, очень быстрого изменения выработки электроэнергии. Данным качеством они принципиально отличаются от тепловых и атомных, которым требуется стабильный режим работы.

Так как население крупных городов в течение суток очень неравномерно потребляет электроэнергию: ночью минимальное потребление, а утром, днем - максимальное, то для снятия этой энергетической неравномерности очень удобно использовать ГЭС. Неравномерность выработки на них электроэнергии определяется, соответственно, неравномерностью сброса воды из верхнего бьефа ГЭС в нижний.

Характерный график внутрисуточного изменения расходов сброса через плотину Камской ГЭС представлен на рисунке 1.

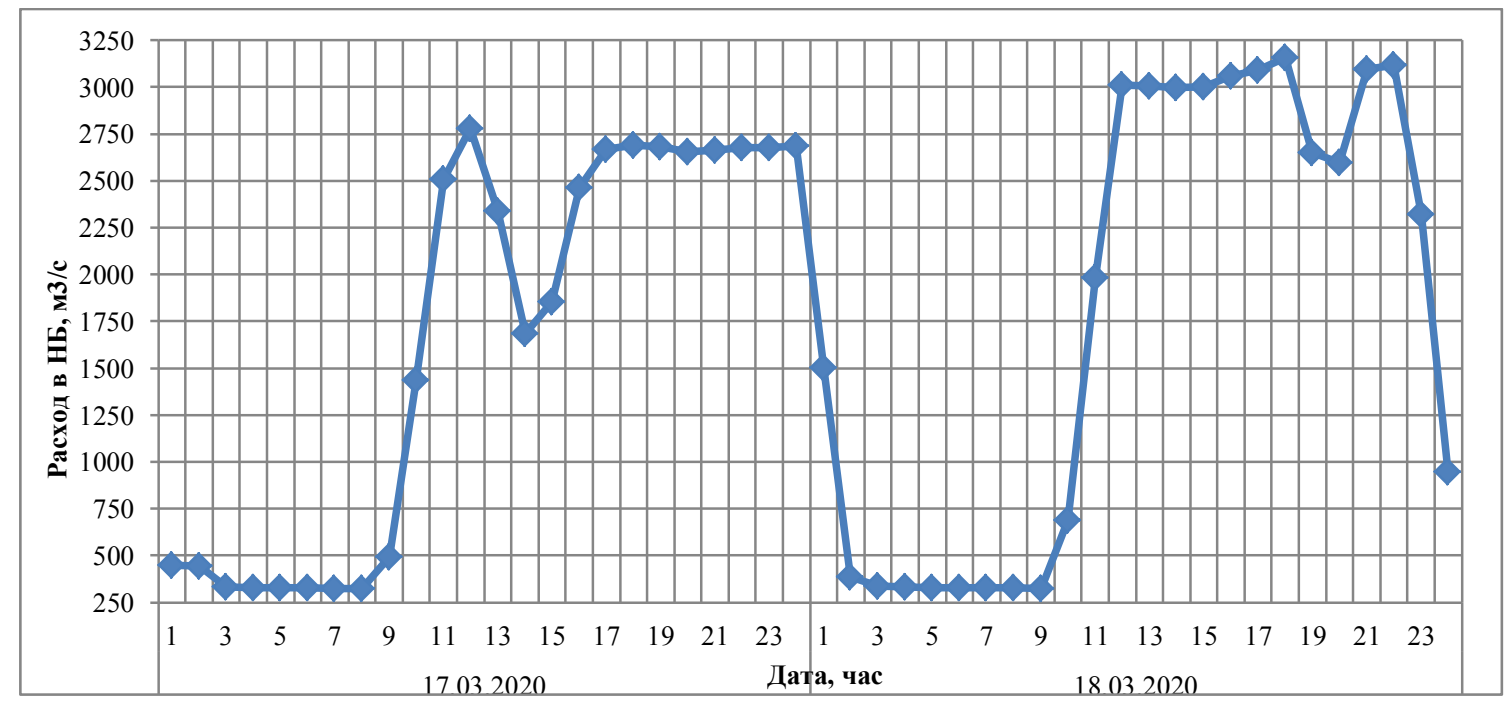

Рис. 1. Хронологический график изменения почасовых расходов сброса воды в нижний бьеф Камского гидроузла за 17 - 18 марта 2020 года

Как видно из рис. 1, в соответствии с изменением потребности электроэнергии в ночной период сброс воды в нижний бьеф минимален и находится на уровне так называемых санитарных сбросов, а утром резко возрастает, затем в ночной период снова резко снижается. Такое резкое изменение расходов сброса воды через плотину ГЭС не может не отражаться на гидродинамическом режиме верхнего бьефа водохранилища. 
Для г. Перми гидродинамика верхнего бьефа Камской ГЭС имеет особое значение, так как она непосредственно отражает на качестве забираемой воды на основном питьевом водозаборе - Чусовских очистных сооружениях. Как показано в [1] в зимний период жесткость забираемой воды, в значительной мере, определяется особенностями слияния рр. Чусовой и Сылвы.

С целью исследования внутрисуточного изменения скоростного режима на Чусовском плесе в районе ЧОС были проведены суточные измерения скорости течения с использованием многопараметрического измерителя течения Valeoport MIDAS ECM. Измерительная вертикаль располагалась 315 м от левого в районе ЧОС в 15,5 км выше плотины Камской ГЭС (рисунок 4). Измерения проводились на верхней границе слоя скачка, уровень воды в водохранилище был $\mathrm{H}_{\text {абс }}-104,92$ м, а отметка расположения прибора $\mathrm{H}_{\text {изм }}-98$ м. Данный прибор позволяет проводить измерения скорости и направления течения, электропроводности, температуры и мутности воды с частотой измерения $1 / \mathrm{c}$. Хронологические графики изменения модуля горизонтальной скорости течения и направления течения представлены на рисунках 2 и 3 . Как следует из рисунка 2 максимум скорости течения $\sim 0,16 \mathrm{м} / \mathrm{c}$ наблюдается $\sim 11^{30}$, затем происходит снижение скорости течения, при этом как следует из рисунка 3 в районе $1^{00}$ начинают формироваться обратное течения, которые устойчиво наблюдаются с $2^{00}$ до $5^{00}$ утра. Затем по мере ослабления инерционного эффекта, оно затухают и доминирующими становятся вновь стоковые течения.

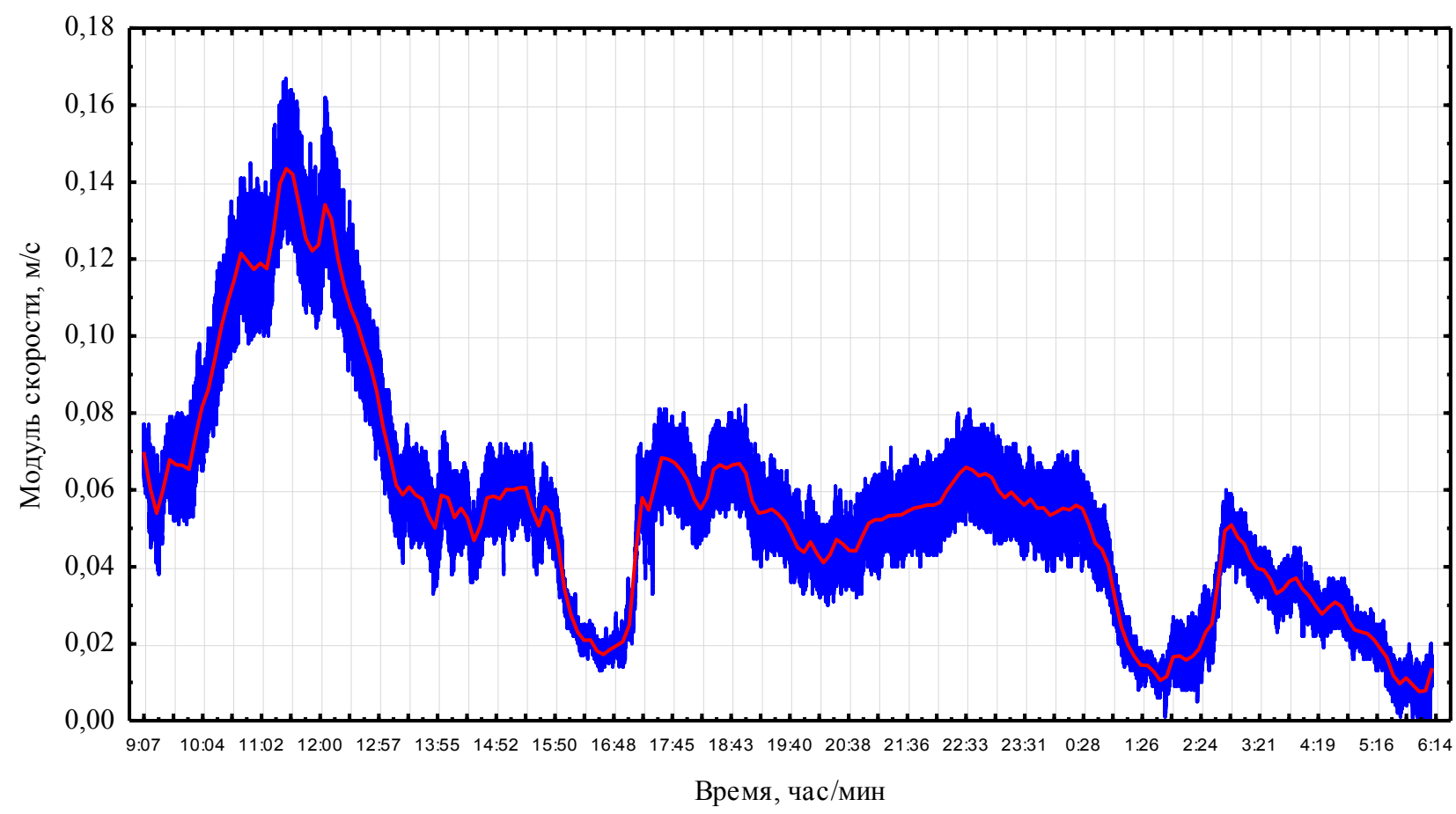

Рис. 2. Изменение значений модуля горизонтальной скорости течения за период времени 17.03.2020 9:07 - 18.03.2020 06:10

Данные обратные течения достаточно хорошо воспроизводятся современными вычислительными средствами даже в 2D приближении.

Расчет проводился с использованием лицензированного, специализированного, гидрологического программного пакета SMS v.11.1, на основе модели RiverFlow2D. Его описание дается в [2]. Данный программный продукт достаточно активно использовался при решении актуальных водохозяйственных задач $[3,4]$. 
На рисунке 4 представлено характерное поле течения при доминировании стоковых течений, а на рисунке 5 - обратных течений, формирующихся при резком изменении расходов сбросов через плотину Камской ГЭС.

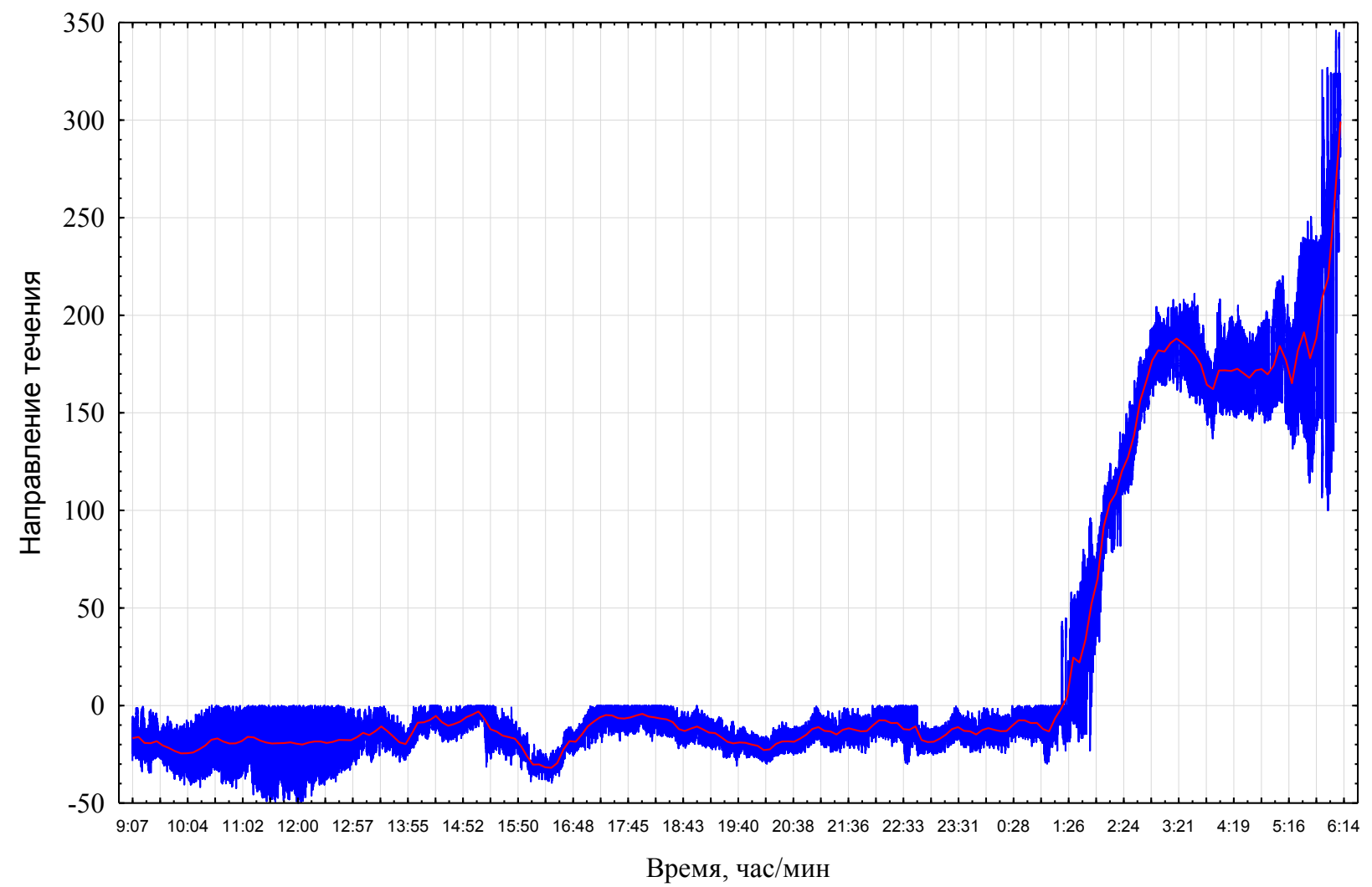

Рис. 3. Хронологический график изменения направления течения за период времени 17.03.2020 9:07 - 18.03.2020 06:10

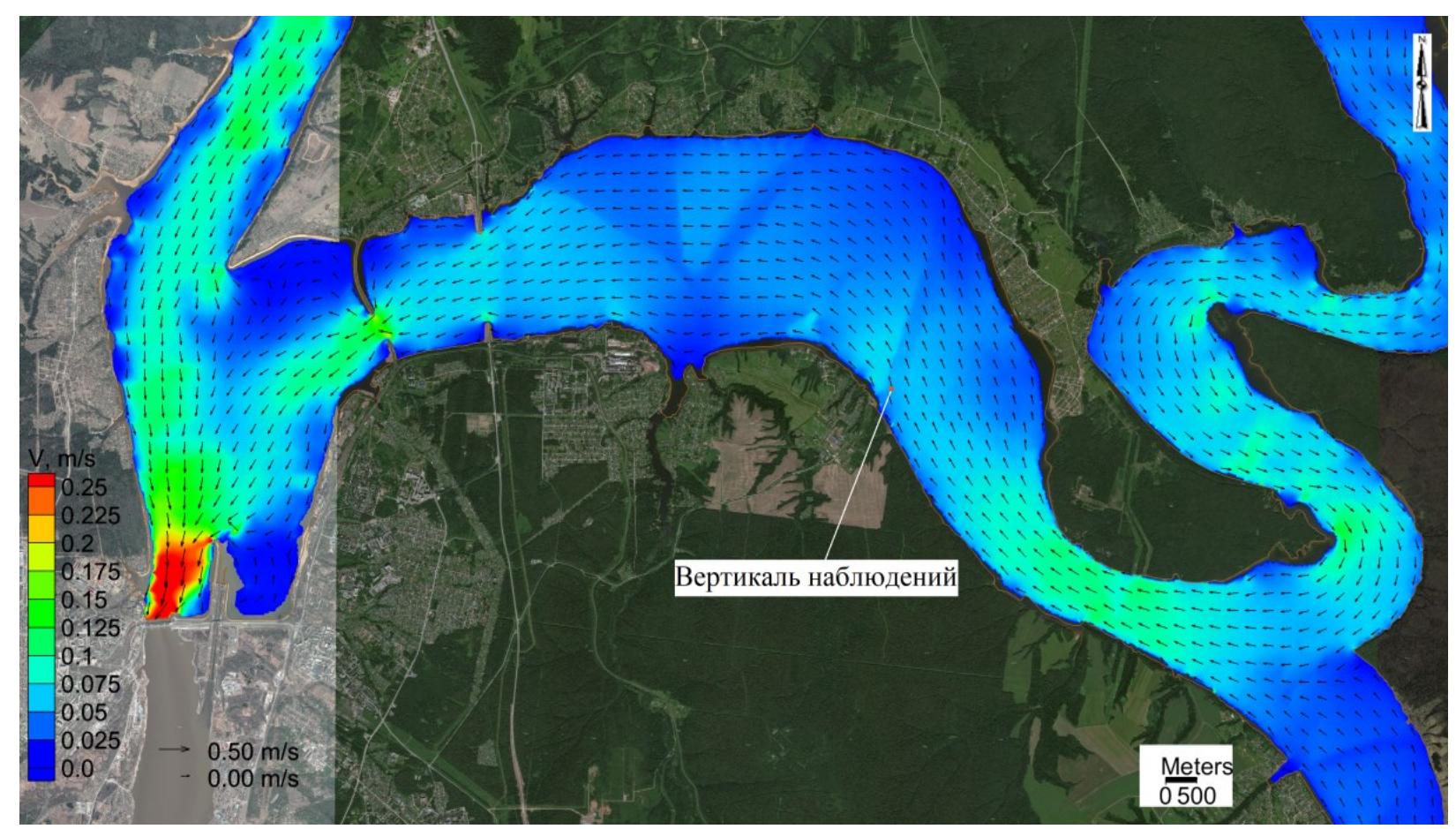

Рис. 4. Характерное поле течения в верхнем бъефе Камской ГЭС при максимальных дневных расходах сброса $2500 \mathrm{~m}^{3} /$ сек 


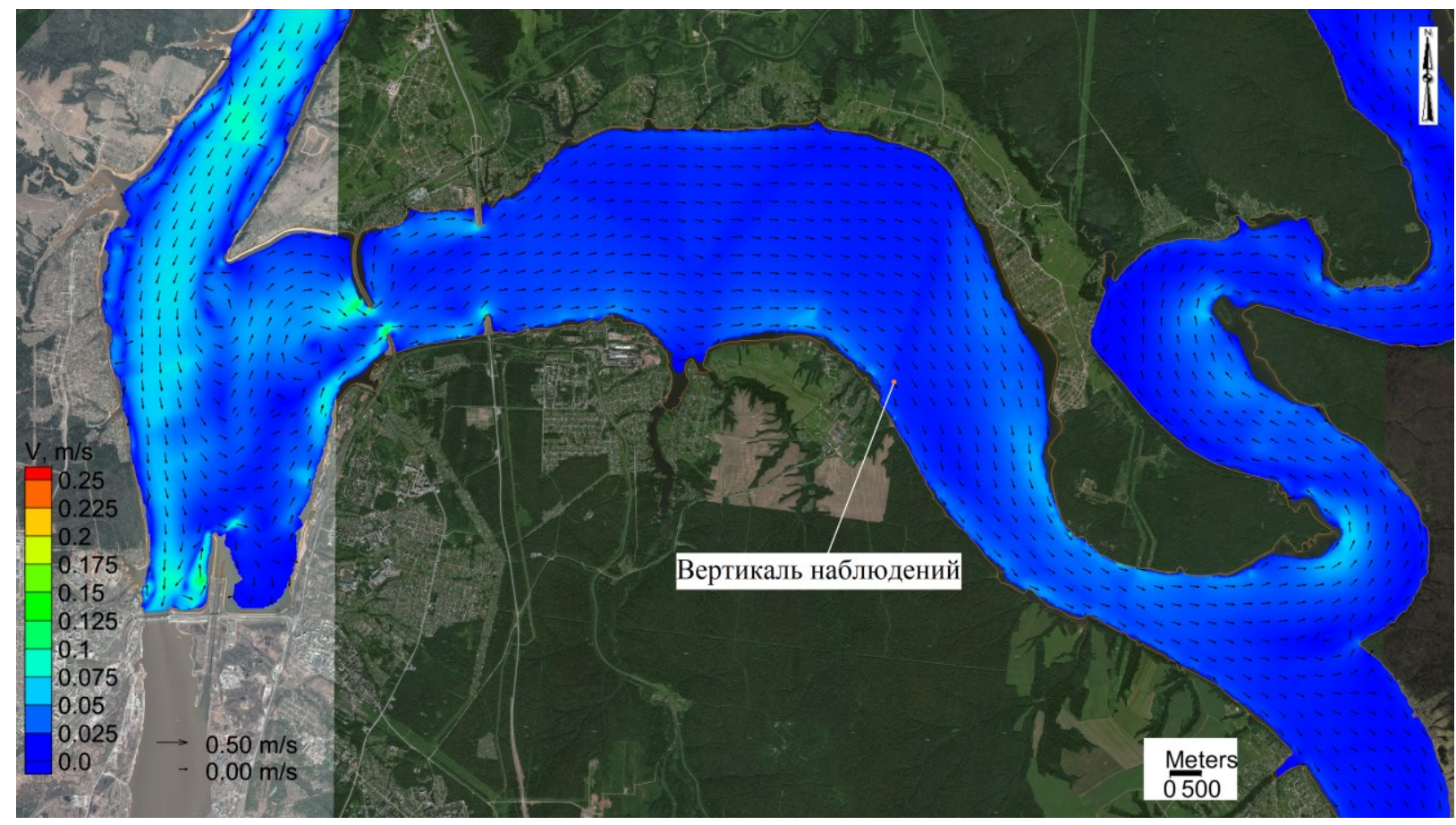

Рис. 5. Характерное поле течения в верхнем бъефе Камской ГЭС при минимальных ночных расходах сброса $330 \mathrm{~m}^{3} /$ сек

Распределение скорости, представленное на рисунках 4 и 5, достаточно хорошо отражает результаты фактических замеров по изменению направления течения (рисунок 3), свидетельствующие о формировании и наличии обратных течений на фоне резкого снижения сбросов воды через плотину Камской ГЭС.

\section{Заключение}

Неравномерность работы Камской ГЭС, нестационарность сброса воды в нижний бьеф очень существенно отражается на гидродинамике верхнего бьефа Камского водохранилища. Соответственно, данные течения требуют не только тщательного дальнейшего измерения, но и их учета при минимизации влияния на хозяйственное использование рассматриваемого участка Камского водохранилища.

\section{БИБЛИОГРАФИЧЕСКИЙ СПИСОК}

1. Lyubimova T., Lepikhin A., Konovalov V., Parshakova Ya., Tiunov A. Formation of the density currents in the zone of confluence of two rivers // Journal of Gydrology. - 2014. - V. 508. - P. 328-342. DOI: 10.1016/j.jhydrol.2013.10.041.

2. RiverFlow2D Two-Dimensional River Dynamics Model August, 2016. - текст электронный // Hydronia LLC: сайт. - URL: http://www.hydronia.com. (дата обращения 12.03.2020).

3. С. 108-119.

4. Лепихин А.П., Любимова Т.П., Ляхин Ю.С., Тиунов А.А., Богомолов А.В., Перепелица Д.И., Паршакова Я.Н. Гидродинамическое моделирование реки Вятки в среднем течении: постановка задачи, результаты расчетов // Водное хоз-во России: проблемы, технологии, управление. - 2013. - № 3. - С. 16-32

5. Lyubimova T., Parshakova Y., Lepikhin A.P., Lyakhin Y., Tiunov A. Application of hydrodynamic modeling in $2 \mathrm{D}$ and $3 \mathrm{D}$ approaches for the imrovement of the recycled water supply systems of large energy complexes based on reservoirs-coolers // International journal of heat and mass transfer. -2019 . - V. 140. - P. 897-908. DOI: 10.1016/j.ijheatmasstransfer.2019.05.105. 